\title{
Bio-psycho-social Intervention for Relapse Prevention among Males with Substance Dependence
}

NEHA SHARMA

\begin{abstract}
Relapse poses a fundamental barrier to the treatment of substance dependence. Preventing relapse is therefore a prerequisite for any attempt to facilitate successful and long-term behavioral changes in substance dependents. Relapse can be caused by biological, psychological and socio-cultural reasons hence this study was aimed to develop and implement a bio-psycho-social intervention program for relapse prevention. 100 male subjects having multiple substance dependence from 16 to 60 years of age were selected through purposive sampling. Subjects were assessed on 'Advance warning of relapse questionnaire' followed by a follow up study through telephonic interview for six months. Two null hypotheses were formulated to see the effect of intervention on relapse prevention. Between two groups research design was used for the study with 50 subjects in each group. Data was analyzed by using $\mathrm{t}$ and $2 \times 2$ contingency $\chi^{2}$ tests. For first hypothesis was significant at 0.01 level and concluded that intervention program reduced advance warning signs of relapse. For second hypothesis $74 \%$ experimental group subjects were abstinent till six months after intervention as compared to $22 \%$ of control group. It was concluded that bio-psycho-social intervention program is significantly effective in relapse prevention among males with substance dependence.
\end{abstract}

Key words: substance dependence, advance warning of relapse, relapse prevention, bio-psycho-social intervention.

The country is flooded with substances that lift you up, cool you down, and turn you upside down. It's normal to start the day with caffeine, in the form of coffee, to take wine with meal, to meet friends for a drink after work, and to end the day with a nightcap. Recent data about substance abuse and dependence shows that in 2012, 7.0\% of whole population (15 to 64 years old) globally uses illicit drugs (World Drug Report, 2016) ${ }^{1}$. In India $18 \%$ of the whole population (25 years of age and above) are engaged in one of another substance abuse. Among them 55.6\% abuse alcohol, $20 \%$ cigarettes, $3.2 \%$ smokeless tobacco, $8.20 \%$ illicit drugs, $6.50 \%$ marijuana/hashish, $0.80 \%$ cocaine, $1.30 \%$ pain reliever, 1.10 stimulants etc (National Survey, 2015) ${ }^{2}$. If we look beyond, a survey shows that 4,859 tones drugs seized from India in 2014 and 16,279 cases were registered for the same. There were $1,83,000$ deaths reported in 2012 because of drug dependence (Mallapur, 2015) ${ }^{3}$. Therefore, going through the present scenario, management and awareness of substance dependence has become a primary challenge for mental health professionals. Thus, the present study is an attempt to contribute in this area and its significance in providing a complete intervention program for relapse prevention. Because substance use disorders are chronic, successful management rather than only detoxification is the goal in treatment.

Approximately $40 \%$ to $60 \%$ of the patients receiving treatment for substance dependence remain abstinent for one year following treatment. The remaining patients may be considered to be in 
some form of relapse (McLellan et al., 2000) ${ }^{4}$. Abstinence includes management of withdrawal symptoms, psychological and social stressors, personal and social demands, manifested in the form of warning signs that can lead to lapse and then cause relapse (Gorski \& Miller, 1986). Therefore, relapse is the biggest challenge for the treatment of substance dependence hence this study was aimed to design a multidimensional relapse prevention program for males with multiple substance dependence.

Here substance dependence is defined as a maladaptive pattern of substance use that leads to clinically significant impairment or distress. Substance dependent individuals show a distinctive pattern of repeated use that usually results in tolerance, withdrawal symptoms and compulsive substance taking (APA, 2000) ${ }^{6}$. Substance dependence affects all areas (biological, psychological and social) of an individual therefore its treatment is also multi-dimensional in nature (Bouis et al., 2007) ${ }^{7}$. Treatment of this disorder starts with detoxification along with other multidimensional therapies like family therapy, and psychotherapies. Relapse is a fundamental barrier in this treatment procedure and preventing relapse is therefore a prerequisite for any attempt to facilitate successful and long-term behavioral changes in substance dependents (Gonzales et al., 2012) ${ }^{8}$. Having a treatment plan is important to recover but quality treatment provided to the person trying to recover is usually the foundation for preventing a relapse. A relapse prevention plan involves preparing for the possibility of a relapse and identifying ways to avoid one.

Before describing intervention program used in this study, relapse prevention is needed to be introduced first. Relapse is a process rather than an event ${ }^{5}$. Relapse is the recurrence of a prior condition usually representing a negative connotation after a period of improvement and in context of substance abuse/ dependence, reinitiation of substance seeking behavior and resumption of use after a period of abstinence. Process of relapse starts from prelapse that is a stage with overwhelming cognitions related to reversal of changed behavior or pattern of behavior (Scrimali \& Grimaldi, 2002, p.65) ${ }^{9}$. Here is resurgence of thoughts and desires consistent with a return to previous functioning. This desire may be triggered by current stressors or may be a spontaneous recovery of associations set in motion by an emotionally proactive memory. If this crucial point is not managed successfully, it leads to lapse and lapse is the stage where the skills needed to go from action to maintenance decrease or are ignored. This is not full return to pre-change pattern but the stage is set for relapse to occur. Affect during lapse may run the gamut from panic to anger to resignation or even relief. Final stage is relapse in which there is a return to behaviors that caused the original referral that had been altered in the action stage (Freeman, Felgoise \& Davis, 2008, p.334-5) ${ }^{10}$.

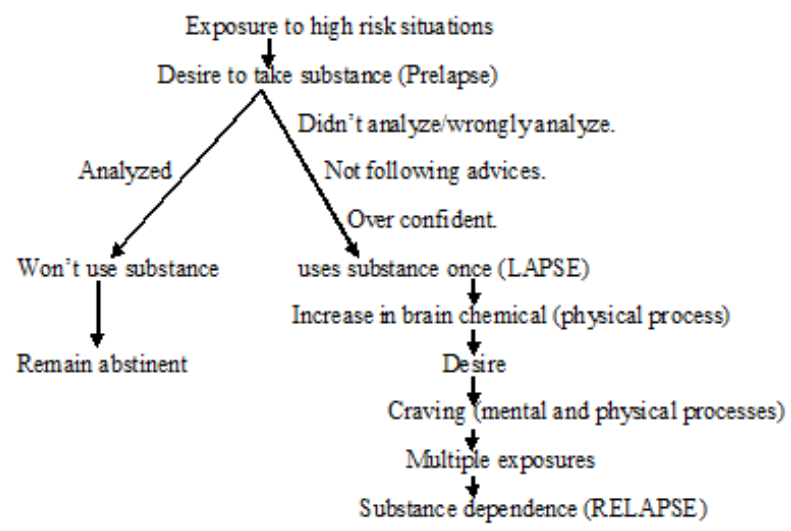

Relapse is resulted from multiple reasons, physical (withdrawal symptoms, body aches etc), psychological (negative mood states, stresses) and social (people, place, things and situations) (Gonzales, Anglin, Beattie \& Glik, 2012) ${ }^{8}$. Mattoo S.K., Chakrabarti S., Anjaiah M., (2009) studied psychosocial factors associated with relapse in men with alcohol and opioid dependence. Patients who had relapsed were significantly more likely to 
have a positive family history of substance use and higher number of previous relapses; to be using maladaptive coping strategies; to have been exposed to a higher total number of 'high risk' situations and have experienced a higher number of undesirable life events (Mattoo, Chakrabarti \& Anjali, 2009) ${ }^{11}$.

Now to prepare person for analyzing/ understanding the high risk situation and to manage it properly, the researcher here gave a complete intervention program to deal with all physical, psychological and social triggers. It involved yoga asana (Pashchimottan asan), relaxation therapy (combination of Progressive Muscular Relaxation and Yoga Nidra), and cognitive behavior therapy (adaptive skills training) along with psycho-education. These are described briefly as:

\section{Yoga therapy}

Yoga therapy is an integrated approach for physiological and psychological wellbeing (Narasimha, Nagarathna \& Nagendra, 2011) ${ }^{12}$. Yogic exercises help in integration of two aspects both at the level of effectors' organ as well as at the level of brain (cerebral cortex and spinal cord). And substance dependence has a brain mechanism that first effects brain functioning and gradually effects the whole body functioning. Person with substance dependence has both physical as well as psychological manifestations. As Slites $(2000)^{13}$ proved that serious withdrawal symptoms among substance dependents require medical aid, but some simple yogic practices can also be useful and these practices should be rather simple, pleasant and relaxing for them (p.48) ${ }^{\mathbf{1 3}}$.

Pashchimottan asana, practiced by the subjects was simple, pleasant and relaxing. This pose stretches the back bone and spinal cord including entire body parts from the head to the heels (Shivanand, 1997, p.36) ${ }^{14}$. An important function of this asana is not only to improve muscle tone and postural reflex but also render the lower centers a greater degree of freedom from inhibitory control of cerebral cortex. It works through two mechanisms, one rhythmic stretching of the muscles with mechanical stimulation of collected tissues and muscular fibers, lining lungs, liver gallbladder, stomach and intestines cause an improvement in their muscle-tone and contractile power which in turn improves their functional capacity (Shukla \& Gehlot, 2014) ${ }^{15}$. And second, activates thalamus, hypothalamic, forebrain and endocrine connections in a subtle manner. Some physical and psychological benefits of this asana are-

Pashchimottan asana powerfully massages all the abdominal organs of the body, stimulates and tones the digestive organs, increases peristalsis and relieves constipation, counteracts obesity and enlarges spleen and liver, regulates the pancreatic functions, provides a valuable aid for those with diabetes or hypoglycemia, mobilizes the joints and increases elasticity in lumbar spine, relieves compression in the spine and sciatica, strengthen and stretches the hamstrings. And as per psychological effects it greatly enhances concentration and mental endurance, invigorate the mind and nervous system, controlling many nervous complaints- This forward bend stretch posture helps a distracted mind unwind and provide grounding. Traditional text claims that Paschimottan asan increases appetite, reduces obesity, and cures diseases like high blood pressure, infertility, insomnia and sinusitis and these physical problems are common in substance dependents (Roy, 1998) ${ }^{16}$.

\section{Relaxation therapy}

Second therapy used in this intervention program was relaxation therapy which was the combination of steps of Jacobson's Progressive Muscular Relaxation (JPMR) and Yog Nidra. Because JPMR works primarily on neuromuscular mechanism and Yoga Nidra on subconscious mind but both of them have physical as well as 
psychological benefits (Shivanand, 1997) ${ }^{14}$. Relaxation therapy included major JPMR steps along with imaginary relaxation as a part of yoga nidra. Jacobson proved the connection between excessive muscular tension and disorders of body and psyche. Jacobson found out that tension, exertion is accompanied with shortening of the muscular fibers that reduces muscular tonus which ultimately decreased the activity of the central nervous system. And relaxation is the contrary of state of excitement and well suited for a general remedy and prophylaxis against psychosomatic disorders. Long-term effects of regular practice of progressive muscle relaxation include: A decrease in generalized anxiety, a decrease in anticipatory anxiety related to phobias, Reduction in the frequency and duration of panic attacks, Improved ability to face phobic situations through graded exposure, Improved concentration, An increased sense of control over moods (Jacobson, 1924) ${ }^{17}$.

Various studies have been done for observing the effect of yoga nidra. It can be defined as an altered state of consciousness. In yoga nidra it is not necessary to concentrate; one should just keep the mind moving from point to point and be aware of every experience. Yoga nidra means sleeping with a trance of awareness. Yoga nidra works on brain functioning through neurological and endocrinal mechanisms. Experimental evidence suggests that the yoga nidra state represents an integrated response by the hypothalamus, the region of the brain serving as control centre for the whole autonomic nervous system. Hypothalamus is richly enervated by nerve fibers from the emotional centres of the limbic system and the amygdala nuclei in the base of the brain. Through this link, our physiological and hormonal responses are directly influenced by our emotions. The hypothalamus also forms a part of the Ascending Reticular Activating System (RAS), the part of the brain stem responsible for the patterns of sleep; arousal and wakefulness. The value of practice of yogic relaxation in prevention of cardiovascular disease has been fairly well recognized and accepted (Cooper, 1979) ${ }^{18}$. In another study conducted by W.S. Agras demonstrated that the drop in blood pressure induced by daily Yoga nidra has a far reaching effect, extending throughout the day and is not nearly a transient effect coincident with the practice session. He found that a reduction in blood pressure and anxiety levels in hypertensive patients continues for twelve months after yoga nidra training. Yoga nidra works on brain functioning through neurological and endocrinal mechanisms (Agras, 1990) ${ }^{19}$.

\section{Cognitive behavior therapy}

Cognitive behavior therapy is a adaptive skills training. It is most important therapy for the treatment of substance dependence. It seems likely that the content of the cognitive behavior therapy approaches, which focus on enhancing commitment to abstinence and supporting commitment systematically through teaching of coping skills, can provide structure and motivation that may be helpful for patients who are initially attempting to overcome co-occurring disorders. Although most of the process of development of substance-use disorders occurs without awareness through a combination of both operant and classical learning processes, coupled with biological changes that occur as the part of the body's adaptation to the presence or absence of the substance, changes are occurring on a cognitive level as well. Expectancies often manifest themselves as cognitions coupled with both physical sensations and affect. These cognitions are often experienced as "urges" to use or "cravings" for the substance, and can serve as proximal stimuli for behavior aimed at obtaining the substance (Tiffany \& Conklin, 2000) ${ }^{20}$. In the present research work, researcher used following treatment protocol from treatment manual given 
by Monti et. al., for cognitive behaviour therapy of substance dependents (Monti, 2002, p. 279-84) ${ }^{21}$

Motivational feedback and generating motivation for change: In this session the focus is upon exploring pros and cons of abstinence. A large body of research has explained that people change, either on their own or with the help of therapist (Prochaska, DiClemente \& Norcross, 1992) 22 , and has provided a foundation for promising approach to increasing motivation for change. Similarly motivational interviewing approach is also completely compatible with cognitive therapy and has proved to be quite effective (Gosky \& Miller, $1986)^{5}$.

Functional analysis: This session is focused on helping the client to identify and introduce situations in which he is at increased risk for substance use. Situations are classified as interpersonal and intrapersonal, because high risk situations (often called "triggers") can be affective states, as well as external events like place, persons, things and situations (Marlatt, 1996) ${ }^{23}$.

Managing urges to use: the focus of this session is on developing the strategies for early identification of precursors to substance use, and planning methods to cope with urges. A variety of methods have been employed to help substance users resist urges to use. Most commonly this involves some versions of thought stopping coupled with a brief decisional balance exercise on the pros and cons of using,- delay action of feeling for at least 15 minutes, or what has been called "urge surfing"simply observing the urge but not the action upon it. In session practice can often bring home the central point of this session: that urges and cravings typically subside on their own.

Managing negative thinking: substance users early in treatment are often subject to a variety of negative thoughts about themselves, their substance use, and their ability to cope with daily living without using substance (Monti, 2002) ${ }^{21}$. Often these negative thought patterns trigger negative affect that, in turn, become a high risk situation for substance use. In this session, participants learn to identify and challenge negative or maladaptive thought patterns. The most frequently used method is to teach Ellis's Antecedents -Beliefs-Consequences-DisputingEffects approach to cognitive restructuring.

Seemingly irrelevant decisions: in this session participants are taught functional analysis as a mean of thinking through the risk potential of various decisions. Often "seemingly irrelevant decisions" can trigger a relapse, so participants are taught to think ahead and evaluate potential course of action, with an eye toward the degree to which these may lead to high -risk situations that may tax coping skills.

Planning for emergencies: the focus is on developing specific "if.....then" action plan that are individualized for each group participant, and involves a hierarchy of coping strategy fails, the participant has a second (sometimes even third strategy) upon which to rely.

Refusal skills: often one of the most difficult challenges for a substance user to confront without using is a direct offer of alcohol or drugs from another person. Although refusing an offer of substance is quite simple in principle (one need to say "no thanks," repeatedly if necessary). In this session participants develop a personal "script" for substance refusal and role play practice encounters using assertive responses to increasingly insistent offers of substances from other group members. Emphasis is placed on assertive responding: body posture, eye contact, tone of voice, and statement content. 
Giving and receiving criticism: In this session, focus is on what to say and how to say it when responding to critical comments from others, as well as how to deliver critical comments to others without becoming angry or confrontational. This session often includes relaxation techniques used to defuse physiological arousal (either anxiety or anger).

Anger management: yet another difficult task of many substance abusers is managing angry responses both towards others and towards their own perceived inability to organize their lives effectively without substances as the focus. This session teaches a basic anger, relaxation strategies to reduce arousal, and cognitive restructuring to assist in defusing angry thoughts and implementing a problem solving approach to anger- inducing encounters. Again role play exercises play an important part in this session.

Increasing pleasure activities: in this session, patients are helped to identify and increasingly engage in pleasurable activities that can provide a substitute for substance abusers. There is then a process of eliciting commitments from participants to begin to engage in these pleasurable activities in a plan throughout the remainder of their treatment.

Problem solving: In this session, the participants are introduced to standardized problem solving developed by D'Zurilla \& Nezu (2006) which consists of a series of steps for effectively identifying a problem, brain storming possible solutions, selecting a solution to implement, implementing the solution then evaluating the efficacy of chosen approach (p.232) ${ }^{24}$.

Developing support network: this session addresses strategies for reinstituting old nonsubstance focused friendships, repairing damaged family relationships. Issues such as repairing damaged relationships with employers and spouse/ domestic partner are central to this session. Psycho-education was also an important aspect during treatment. It was used during adaptive skills training. Intervention was followed by post assessment of advance warning signs of relapse which included all the triggers (physical symptoms, beliefs, things and situations) responsible for lapse and relapse.

\section{METHODOLOGY}

Research problems: Does bio-psycho-social intervention program reduces advance warning signs of relapse? Does bio-psycho-social intervention program help in relapse prevention?

Hypothesis: Two directional hypotheses were formulated as follows:

1) Bio-psycho-social intervention program has significant effect on advanced warning signs of relapse.

2) Bio-psycho-social intervention program has significant effect on relapse prevention.

Sample: In this study population was males with multiple substance dependence above the age of 16 years and abusing substances at least for the duration of two years prior to the admission and hospitalized for the treatment.

Inclusion criterion: males with multiple substance dependence above the age of 16 years and abusing substances at least for the duration of two years prior to the admission and hospitalized for the treatment. Subjects who were hospitalized for seven to ten days were taken as subjects. They could have recovered from severe withdrawal symptoms and could actively participate in the intervention program.

Exclusion criteria: The patients of substance dependence with psychosis in co morbidity were not included in the sample and patients who were reluctant or forcefully hospitalized. 
Sampling: Subjects were selected by using Purposive sampling method and divided into experimental and control group. Total number of subjects was 100, with 50 participants in each group. For data collection, between two groups research design was used, i.e., each group was assessed twice on the same questionnaire. Assessment and intervention started 7 to 10 days of hospitalization until the subjects get rid of sever withdrawal symptoms. In first attempt researcher selected the subjects for experimental group on which bio-psycho-social intervention program was administered for 35 days. After completing the intervention program, the researcher selected another group from the same setting as the control group, which did not go through the intervention program. These groups were taken from the same settings one after another. The reason behind taking the groups separately was to avoid therapeutic contamination. If groups were considered simultaneously, there were chances of discussion and learning of therapeutic programs among patients, which might affect the results. These groups were similar initially on the basis of pre-test means and in same hospital setting. The reason behind using this research design was to control the effect of medication and other treatments given to the subjects during hospitalization.
Tool: Advance Warning of Relapse (AWARE) questionnaire was used to predict the occurrence of relapse after intervention. This questionnaire was initially designed by Gorski and Miller in 1982 and later refined by Miller and Harris, in 2000 (version-3). This is a self report questionnaire with 28 items in English to be rated on 1-7 rating scale.

Procedure: subjects were assessed on AWARE questionnaire after 7-10 days of hospitalization, followed by the intervention program for 35 days. Intervention was given for around 2 hours daily (15 minutes yoga asana followed by 30 minutes relaxation therapy and 30 to 45 minutes adaptive skills training). Yoga asana and relaxation therapy were practiced in group in morning time and adaptive skills training was given individually in the afternoon. Then the same group was assessed on the AWARE questionnaire after 35 days of intervention. Similarly, the control group was assessed on the AWARE questionnaire twice at the interval of 35 days.

Follow up Study: subjects and their family members were asked telephonically about the relapse in the duration of one month till 6 months after treatment. Only fully abstinent subjects were taken under consideration.

\section{RESULTS}

Hypothesis (1): Bio-psycho-social intervention program has significant effect on advance warning signs of relapse.

Table -1 showing difference between pre - post mean scores for experimental \& control groups.

\begin{tabular}{|l|c|c|c|c|c|}
\hline & N & $\begin{array}{c}\text { Pre-test mean } \\
\text { scores }\end{array}$ & SD & $\begin{array}{c}\text { Post-test mean } \\
\text { scores }\end{array}$ & SD \\
\hline Experimental Group & 50 & 99 & 24.36 & 56 & 6.30 \\
\hline Control Group & 50 & 103 & 21.6 & 67 & 5.80 \\
\hline Correlation & \multicolumn{3}{|c|}{0.65} & \multicolumn{2}{|c|}{0.64} \\
\hline t- values & \multicolumn{3}{|c|}{1.14} & $\mathbf{1 1 . 8 2}$ \\
\hline
\end{tabular}




\begin{tabular}{|l|c|c|}
\hline Significance level & $\mathrm{P} \approx 0.05$ level & $\mathrm{P}=0.01$ level \\
\hline
\end{tabular}

$$
\text { Df }=97
$$

Hypothesis2: Bio-psycho-social intervention program has significant effect on relapse prevention. Table -2 showing number of subjects abstinent and relapsed after 6 months after treatment.

\begin{tabular}{|l|l|l|l|}
\hline & Abstinent subjects & Relapsed subjects & N \\
\hline Experimental Group & 28 & 10 & 38 \\
\hline Control Group & 08 & 28 & 36 \\
\hline & 36 & 38 & 74 \\
\hline
\end{tabular}

$\mathrm{Df}=1, \chi^{2}=9.26, \mathrm{P}=0.01$ level

From the observed data $74 \%$ subjects were abstinent till 06 months from experimental group as compares to $22 \%$ subjects of control group.

\section{DISCUSSION}

In table1, two t-values are being calculated, one between pre-test mean scores of both groups and second for post-test mean scores. Purpose to calculate pre- test mean scores' difference is to ensure that both groups are same initially before the comparison. As the $t$ value for pre test means is not significant at .05 level hence it can be interpreted that both groups do not differ from each other. Post test mean scores has significant $t$ value at 0.01 level that means hypothesis 1 is accepted. Hence it can be interpreted that biopsycho-social intervention program has significant effect on advance warning signs of relapse. This intervention program reduces the advance warning signs of relapse as shown by the mean scores. In table 2, again $\chi^{2}$ value is significant at 0.01 level and hypothesis 2 is also accepted that means biopsycho-social intervention program has significant effect on relapse prevention.

After the implementation of this intervention program $74 \%$ subjects were abstinent till 6 months as compared to $22 \%$ from control group. Effectiveness of this intervention program and results of the study are supported by some researches as discussed. Chauhan S. K., (1997) studied the role of yogic exercises in the withdrawal symptoms of drug-addicts. In his

study, 60 addicts were given regular yogic exercises daily for about 45 minutes for 15 days.

The results revealed that yogic exercises brought about significant improvement in the withdrawal symptoms of drug addicts as well as in their general behavior as compared to control group subjects. These withdrawal symptoms can be responsible for relapse or can act as warning signs for relapse (Chauhan, 1992) ${ }^{25}$. Similarly in this study yogic practice of intervention program also used to reduce advance warning signs of relapse. Carpenter et al., (2008) tested the relative efficacy of behavior therapy for depression in drug dependence against a structured relaxation intervention (REL) for substance abuse. The findings suggested that both behaviour- and relaxation-based approaches show promise for treating co-morbid depression in drug dependent populations.

Future work should examine combining or modifying these interventions to target substance use more directly and include values based 
methods for increasing more adaptive behavior patterns (Kenneth et al., 2008) ${ }^{26}$. As per statements in AWARE questionnaire, feeling of depression is a warning sign for relapse and behavior therapy as adaptive skills training was used in the intervention program for the same. In another study, Dodge (1991) reviewed relaxation training as a nursing intervention for substance abusers, a multi substance abuser were used to demonstrate the clinical status of drug dependence, and how relaxation techniques can be used in treatment was observed. Final recommendation was drawn from the literature and case studies, and observed a significant effect of relaxation training on multiple substance dependents (Vincent, 1991) ${ }^{27}$. Also Klajner et al., (1984) reviewed the efficacy of relaxation training as a treatment for alcohol and drug abuse and directions for future research derived. A relaxation procedure, notably progressive muscular relaxation and meditation, was used for anxiety treatment. Consequently, the empirical support for the effectiveness of relaxation training as a treatment for substance abuse in general was significant ${ }^{28}$.

For the second hypothesis, result shows that both groups differ significantly and 74\% subjects of the experimental group prevented relapse as compared to $22 \%$ of the control group. According to McLellan, Lewis, O'Brien, \& Kleber, 2000 , approximately $40 \%$ to $60 \%$ of patients receiving treatment for substance dependence remain abstinent for one year following treatment. The remaining patients may be considered to be in some form of relapse (McLellan, Lewis, O'Brine \& Kleber, 2000) ${ }^{\mathbf{4}}$. And in this study abstinence percentage is comparatively higher, therefore it can be interpreted that this intervention program is efficient for relapse prevention. Monti et al., (1997) studied brief coping skills treatment for cocaine abuse: substance use outcomes at three months. It involved functional analysis of high risk situations and coping skills training based on the functional analysis. Clients who received coping skills training had significantly fewer cocaine use days and the length of their longest binge was significantly shorter during the 3-month follow-up period compared to clients in the control condition (Monti et al., 1997) ${ }^{29}$. Jena R., Sharma M., Kumar R. (2004) studied the role of cognitive behaviour therapy in nicotine cessation among impatient substance abusers (Jena, Sharma and Kumar, 2004) ${ }^{30}$. Sharner, Eckman, Roberts \& Fullar, (2003) evaluated the effect of novel treatment in persons who had both schizophrenia and substance abuse by in cooperating cognitive behaviour drug relapse prevention strategies into a skills training method originally developed to teach social and independent living skills and both studies has significant results towards cognitive behavior therapies $^{31}$.

Use of multidimensional therapy especially yoga therapy, relaxation therapy and adaptive skills training with psycho- education is supported by many researches therefore it is most effective and standard treatment program for relapse prevention among substance dependence disorder.

\section{CONCLUSION}

This clinical study was conducted on males with multiple substance dependence, 16-60 years of age, having history of substance dependence for at least 2 years. Aim was to implement a multidimensional intervention program (yoga therapy, relaxation therapy and adaptive skills training with psycho- education) for relapse prevention and to do follow up study to see the abstinence rate. Results showed significant reduction in advance warning signs of relapse and prevented $74 \%$ of experimental group subjects from relapse. Hence it can be concluded that use of multidimensional therapy especially yoga therapy, relaxation therapy and adaptive skills training with psycho- education as also supported by many other researches is the most effective and 
standard treatment program for relapse prevention among substance dependence disorder.

$============================$
NEHA SHARMA, Research Associate, Defence
Institute of Psychological Research, DRDO,
Timarpur, New Delhi (India)
==================================

\section{REFERENCE}

Agras, W. S. (1990). Surreptitious drug use by patients in a panic disorder Study. American Journal of Psychiatry, 147(4), 507-509.

APA (2000). Diagnostic and statistical manual of mental disorders (4th Ed., Text Revision). Washington, DC: American Psychiatric Association

Bouis, S., Reif, S., Whetten, K. Scovil, J., Murray, A. \& Swartz, M. (2007). An Integrated, Multidimensional Treatment Model for Individuals Living with HIV, Mental Illness, and Substance Abuse. Health \& Social Work, 32(4), 268-278.

Carpenter, K.M., Smith, J.L., Aharonovich, E. \& Nunes, E. V. (2008). Developing therapies for depression in drug dependence: Results of a stage1 therapy study. The American Journal of Drug and Alcohol Abuse, 34(5), 642-652.

Chauhan, S. K. S. (1992). Role of yogic exercises in the withdrawal symptoms of drug-addicts. Yoga Mimamsa, 30(4), 21-23.

Cooper, M. J. (1979). A relaxation technique in the management of hypercholesterolemia. Journal of Human Stress, 5(4), 24-27.

D'Zurilla, T. J. \& Nezu, A.M. (2006). Problem solving training manual. Problem Solving Therapy: a positive approach to clinical intervention ( $3^{\text {rd }}$ Edition). New York: Springer publishing company.

Dodge, V. H. (1991). Relaxation training: A nursing intervention for substance abusers. Archives of Psychiatric Nursing, 5(2), 99-104.

Freeman, A., Felgoise, H.S. \& Davis, D. D. (2008). Clinical Psychology: Integrating Science and Practice. New Delhi: Wiley Publication.

Gonzales, R., Anglin, M.D., Beattie, R. \& Glik, D.C. (2012). Understanding Recovery Barriers: Youth Perceptions about
Substance Use Relapse. American Journal of Health and Behaviour, 36(5), 602-614.

Gorski, T. T. \& Miller, M. (1986). Staying Sober: A Guide for Relapse Prevention. New Jersey: Independence Press. Retrieved from https://books.google.co.in/books/about/staying_sober.

Jacobson, E. (1924). The technique of progressive relaxation. Journal of Nervous \& Mental Disease, 60(6), 568-578.

Jena, R., Sharma, M. \& Kumar, R. (2004). Enhancing nicotine cessation among inpatients substance abusers through cognitive behaviour therapy. Indian Journal of Clinical Psychology, 31(2), 117-120.

Kenneth, M., Carpenter, J.L., Smith, E. A. \& Edward, V.N. (2008). Developing Therapies for Depression in Drug Dependence: Results of a Stage 1 Therapy Study. The American Journal of Drug and Alcohol Abuse, 34(5), $642-652$.

Klajner, F., Hartman, L. M. \& Sobell, M. B. (1984). Treatment of substance abuse by relaxation training: A review of its rationale, efficacy and mechanisms. Addictive Behaviours, 9(1), 41-55.

Mallapur, C. (2015). India soaring drug problem: $45 \%$ rise in seizures. Annexure referred to in reply to question no. 227 for answer in Lok Sabha, $09^{\text {th }}$ Dec 2014. Retrieved from www.indiaspend.com/cover-story/indias-soaring-drug-problem-455risein-seizers-26787.

Marlatt, G. (1996). Taxonomy of High-Risk Situations for Alcohol Relapse: Evolution and Development ofa Cognitive-Behavioral Model. Addiction, 91(12), 141-159.

Mattoo, S. K., Chakrabarti, S. \& Anjaiah, M. (2009). Psychosocial factors associated with relapse in men with alcohol and opioid dependence. Indian Journal of Medical Research, 130, 702-708.

Mattoo, S. K., Chakrabarti, S. \& Anjaiah, M. (2009). Psychosocial factors associated with relapse in men with alcohol or opioid dependence. The Indian Journal of Medical Research, 130(6), 702-8.

McLellan, A. P., Lewis, D. C., O'Brien, C. P., \& Kleber, H. D. (2000). Drug dependence, A Chronic Medical Illness: Implications for Treatment, Insurance, and Outcome Evaluation. Journal of the American Medical Association, 284(13), 1689-1695. 
Monti, M. P., Rohsenow, D. J., Michale, E., Martin, R.A. \&

Abrams, D. B. (1997). Brief coping skills treatment for cocaine abuse: substance use outcomes at three months. Journal of Addiction, 92(12), 1717-1728.

Monti, P. (2002). Cognitive Behavioural Coping Skills Therapy for Adults. New York: John Wiley \& Sons Publishers.

Narasimhan, L., Nagarathna, R. \& Nagendra, H. R. (2011). Effect of integrated yogic practices on positive and negative emotions in healthy adults. International Journal of Yoga, 4(1), 13-19.

National Survey (2015). National survey on drug abuse (20132015). National Institute on Drug Abuse. Retrieved from https://www.drugabuse.gov/national-survey-drug-use-health.

Prochaska, J.O., DiClemente, C.C., \& Norcross, J.C. (1992). In search of how people change: Applications to addictive behaviours. American Psychologists, 276(23), 1271-8.

Roy, S. D. (1998). Yoga Exercises, Physiology and Psychic Processes. New Delhi: Jaypee Brothers Medical Publishers Pvt Ltd.

Scrimali, T. \& Grimaldi, L. (2002). Cognitive psychotherapy towards a new millanium- scientific foundations and clinical practice. New York: Springer Science-Bussiness Media.
Sharner, A., Eckman, T., Roberts, L.J. \& Fullar, T. (2003).

Feasibility of skills training approach to reduce substance dependence among individuals with Schizophrenia. Journal of Behaviour Therapy and Experimental Psychiatry, 22(3), 203-210.

Shivanand, S. (1997). Practical Lessons in Yoga. ( $8^{\text {th }}$ Edition). Tehri Garhwal: A Devine Life Society Publication.

Shukla, R. \& Gehlot, S. (2014). Response of Paschimottanasana and Kapalbhati on anthropometric parameters in obese individuals. International Journal of Research in Ayurveda and Pharmacy, 5(3), 256-260.

Slites, M. (2000). Structural Yoga therapy: Adapting to the Individual. San Francisco : Weiser Books.

Tiffany, S. T. \& Conklin, C. A. (2000). A cognitive Processing Model of Alcohol Craving and Compulsive Alcohol Use. Addiction, 95(8), 145-154.

Vincent, H. D. (1991). Relaxation training: A nursing intervention for substance abusers. Archives of Psychiatric Nursing, 5(2), 99-104.

World Drug Report (2016). United Nations office on Drugs and Crime, New York. Retrieved from https://www.unodc.org>wrd2016 